\title{
Ultimate Population Size under Changed Age Specific Fertility Schedule
}

\author{
Roshan Aryal ${ }^{1}$ and T.R. Aryal ${ }^{2}$ \\ ${ }^{1}$ St. Xavier College, Maitighar, Kathmandu, Nepal \\ ${ }^{2}$ Central Department of Statistics \\ Tribhuvan University, Kathmandu, Nepal \\ E-mail: traryal@gmail.com
}

\begin{abstract}
This paper attempts to obtain ultimate population size under changed age specific fertility schedule. The reduction in fertility under exponential and linear decline has been discussed in order to obtain ultimate population size. A concept has been suggested to obtain ultimate population size by combining both exponential and linear decline pattern in age schedule due to faster reduction in fertility at the beginning and thereafter slower declining rate in fertility age schedule.
\end{abstract}

Keywords: Ultimate population size, exponential decline, age specific fertility, stationary, replacement level.

\section{INTRODUCTION}

The concepts to obtain ultimate population size under changed in fertility schedule with age structures has been well established to the population scientists. Female population has been considered in order to model population projection where such population is closed to migration under constant pattern of fertility and mortality overtime that may give a stable condition of population at fixed age schedules by increasing the size of population with a constant growth rate (Aryal 2014, Islam 2001). The constant and fixed size of the population is considered as the stationery state or replacement level of population where the growth rate becomes zero. Growth models have been developed to study the population in different situation of fertility schedule especially under stable/stationary conditions where stable population theory emphasizes to project future size of population beyond the assumptions of constant of vital rates (Aryal 2014, Coale 1972, Mitra 1990) and also made an effort to study population under varying path of fertility schedules (Aryal 2013, Islam 2001, Keyfitz 1977, Lotka 1907, Mitra 1985).

The idea developed by Frauenthal (1975) to study an abrupt shift in fertility schedule and the birth trajectory was well recognized among demographers. Symbolically the birth trajectory is given as:

$B(t)=\rho b e^{r t}$ at time $\mathrm{t}$ for $0<t \leq a$

where ' $\mathrm{a}$ ' is the lower limit of the reproductive period and $\rho$ is the positive constant provided that $0<\rho<1$. The concept introduced by Mitra (1976) indicated that the age patterns depend abruptly with changed in fertility schedule and it is given as: $m(x, t)=e^{-r x} m(x)$

and the birth trajectory is given as:

$$
B(t)=b e^{-r t} \int_{0}^{\infty} e^{-2 r x} p(x) m(x) d x \text { for } t \leq a .
$$

In this context, this paper attempts to obtain ultimate population size under changed age structure with a varying fertility schedules.

\section{MODEL}

The application of the birth trajectory has been well established for the projection of future population in the stability condition (Aryal 2014). Obviously, there are different types of reduction in fertility schedule in order to obtain the population size under stable and stationery conditions. In this line, several researchers have paid their attention to develop model in order to limit future population at replacement level among developing and underdeveloped countries (Aryal 2014, Frauenthal 1975, Pathak \& Rama 1985, Yadava 1993). It is wellknown fact that population growth rate is approaching to zero $(\mathrm{r}=0)$, implies that the stable population size approaching to be fixed, which population reducing to stationary or replacement level. Assuming that $\mathrm{m}(\mathrm{x})$ is the age specific fertility rate (ASFR) and $\mathrm{R}_{0}$ is the net reproduction rate (NNR), then the population becomes at replacement level. Symbolically, it is given as:

$m(x)=\frac{m(x)}{R_{0}}$ 
The population size does not depend only with the eduction of fertility but it has several other population arameters responsible on it.

In this connection, Keyfitz (1971) obtained the ltimate population size $(\mathrm{P})$ by considering the value of JNR is unity, $\left(R_{0}^{*} \Rightarrow 1\right)$, when the ASFR $\mathrm{m}(\mathrm{x})$ is hanged to $\frac{m(x)}{R_{0}}$. Symbolically,

$P=\frac{b e_{0}^{0} m(x)}{\mu r}\left(1-\frac{1}{R_{0}}\right)$

where $b$ is the number of births in a year at survey oint, $e_{0}^{0}$ is the expectation of life at birth, $\mu$ is the nean age of childbearing in stationary population, and ther notations have their usual meanings.

In abrupt change in fertility schedule has not esponsible, which may due to presence of momentum, he population would increase by a factor ' $A$ ' implies hat $e^{r A}$ if it is accepted ' $\mathrm{A}$ ' years of times to reach at tationary level. Studied pointed out that even after lelay of 'A' years, stationary fertility schedule may not bruptly changed and fertility reduction may be the unction of time, mortality, age and socio-economic tatus (Aryal 2011, Pathak \& Ram 1985, Yadava 993). With the concept of Ryder (1975) and xpressions of (1) and (2), the ultimate population size ome out to be:

$$
P=\frac{b e_{0}^{0}}{\mu r}\left(1-\frac{1}{R_{0}}\right) e^{\frac{r A}{2}}
$$

$\mathrm{f}$ fertility schedule $\mathrm{m}(\mathrm{x})$ declines with exponentially Coale 1972), the ultimate population size come out to 'e

$$
\begin{array}{rlrl}
D & =b e_{0}^{0} e^{r\left(A-T+\frac{3 T^{2}}{32 A}\right)} & & \text { if } A<\frac{3}{4} T \\
& =b e_{0}^{0} e^{\frac{r(A-T)}{2}} & \text { if } A \geq \frac{3}{4} T
\end{array}
$$

vhere $T \cong \frac{i n R_{0}}{r}$ is the mean length of generation.

here are several reduction patterns in fertility that ave been discussed in the literatures (Aryal 2014, oale 1972, Keyfitz 1971, Ryder 1975, Kulkarni 976). Among these, the reduction of fertility schedule hrough exponentially and linearly are discussed below. $\mathrm{n}$ case of exponential decline in fertility, the ASFR is ;iven below:

$$
m(x, t)= \begin{cases}m(x) & \text { if } t<0 \\ m(x) e^{k t} & \text { if } 0<t<A \\ \frac{m(x)}{R_{0}} & \text { if } A \leq t\end{cases}
$$

where $k=-\ln \frac{R_{0}}{A}$, which come out to be:

$$
e^{k t}=\frac{1}{R_{0}}
$$

The ultimate population size under such reduction of fertility is :

$$
P=\frac{b e_{0}^{0}}{\mu r}\left(\frac{T}{T-A}\right)\left(1-\frac{e^{r A}}{R_{0}}\right) \quad \text { if } A \leq \alpha
$$

where $\alpha$ is the lower limit of the reproduction.

In case of linear decline in fertility, the ASFR is given below:

$$
m(x, t)=\left\{\begin{array}{l}
m(x) \quad \text { if } t<0 \\
\frac{m(x)(A-t)}{A}+\frac{m(x) t}{R_{0} A} \quad \text { if } \quad 0 \leq t<A \\
\frac{m(x)}{R_{0}} \quad \text { if } A \leq t
\end{array}\right.
$$

The ultimate population size come out to be :

$$
P=\frac{b e_{0}^{0}}{\mu r^{2} A}\left(1-\frac{1}{R_{0}}\right)\left(e^{r A}-1\right) \quad \text { if } A \leq \alpha
$$

The reduction of fertility schedule changed abruptly in some of the society; however it depends on socioeconomic status (Aryal 2011, Mitra 1976). The expression presented under the condition with ASFR remains constant proportion at all the ages of reproduction, which is one of the limitations. Indeed, reduction of fertility at replacement level would naturally higher among older women as compared to younger women. It is assumed that ASFR $\mathrm{m}(\mathrm{x})$ is equivalent to $m^{*}(x)=e^{-r x} m(x)$ instead of $\frac{m(x)}{R_{0}}$.

Under such condition of a changed in fertility schedule, ultimate population size can be computed. The reduction of fertility schedule under several conditions follows exponential or linear decline, however in a higher fertility schedule, the exponential decline would well approximate the ultimate population whereas in lower fertility schedule, the linear decline would well 
approximate ultimate population size. It is suggested that to obtain ultimate population size, both combining the exponential and linear decline may be appropriate where fertility reduction is faster at the beginning age schedules whereas slower at the older age schedule in the population.

Finally, the model discussed above considers only female population $\left(=P_{f}(t)\right)$. It is therefore, the male population $\left(=P_{m}(t)\right)$ can be obtained using following expression.

$$
P_{m}(t)=\frac{e_{m}^{0}}{e_{f}^{0}} \times P_{f}(t) \times S R
$$

where $P_{m}(t)$ and $P_{f}(t)$ be the male and female population at time trespectively, $e_{m}^{0}$ and $e_{f}^{0}$ refer to the life expectancy for male and female population respectively, and SR represents the sex ratio at birth.

\section{CONCLUSION}

The present paper explores modeling concept to obtain ultimate population size under changed fertility schedule. The reduction in fertility schedule under different age structures can be expressed both exponential and linear decline in order to obtain the ultimate population size. It is suggested that to obtain the ultimate population size by combining both exponential and linear decline patterns in the age structures, which may be due to the faster reduction in fertility at the beginning age schedules whereas thereafter the reduction of fertility decline slower rate. If the reliable data are available, the ultimate population size under changed in age specific fertility schedule would easily be computed.

\section{REFERENCES}

Aryal, T.R. 2011. Fertility Dynamics of Nepal. Ekta Books, Kathmandu, Nepal.

Aryal, T.R. 2013. Application of demographic models to investigate levels, differentials and determinants of fertility of Nepal. Journal of Institutes of Science and Technology 18(1):148-156.
Aryal, I.K. 2014. Population projection under changing fertility conditions. Journal of Institutes of Science and Technology 19(2): 86-88.

Coale, A.J. 1972. The growth and structure of human populations: a mathematical investigation. Princeton, Princeton University Press, New Jarsey.

Frauenthal, J.C. 1975. Birth trajectory under changing fertility conditions. Demography 12: 447-454.

Islam, S. 2001. Some demographic models and their applications: particular references to Bangladesh. PhD thesis, Department of Statistics, BHU.

Kulkarni, P.M. 1976. Growth of a population after reduction in fertility. Newsletter 11(1).

Keyfitz, N. 1977. Applied Mathematical Demography. New York. John Wiley and Sons.

Keyfitz, N. 1971. On the momentum of population growth. Demography 8: 71-80.

Lotka, A.J. 1907. Mode of growth of material aggregates. American Journal of Science 24:199-216.

Mitra, S. 1976. Influence of instantaneous fertility decline to replacement level on population growth: alternative models. Demography 13:513-519.

Mitra, S. 1985. A model of changing net maternity rates leading to stability. Demography India 14(1): 130-37.

Mitra, S. 1990. A birth model with oscillating rate of growth. Janasamkhya 8(1): 35-40.

Pathak, K.B. and F. Ram. 1985. Trends in reproductive values of the females and momentum of a population growth: analysis for the major states of India. IIPS, Bombay, India.

Ryder, N.B. 1975. Notes on stationary population. Population Index 41(1): 3-28.

Yadav, S.N. 1993. On some migration and population growth models. $\mathrm{PhD}$ thesis, Department of Statistics, BHU. 